\title{
High Speed Digital Protection of EHV Line Using Travelling Waves
}

\author{
Harpreet Kaur ${ }^{1}$, Dr. Gursewak Singh Brar ${ }^{2}$ \\ ${ }^{1}$ Baba Banda Singh Bahadur Engineering College, Fatehgarh Sahib \\ ${ }^{2}$ Associate Professor and Head EE, Baba Banda Singh Bahadur Engineering College Fatehgarh Sahib
}

\begin{abstract}
Extra High Voltage (EHV) transmission lines are designed to transfer sizably voluminous amount of potency from one location to another. The length exposed to the environment is a major reason for occurrence of faults on the lines. A fault on a high voltage transmission line affects the stability of the overall power system, which sometimes leads to aeonian damage of the equipment. Relays are developed and installed to bulwark the lines. The transmission line aegis relays, in the industry, are predicated on the fundamental frequency components of the voltages and currents. These relays need at least one fundamental frequency cycle for performing the aegis operation. In this paper digital techniques which use travelling waves for auspice of EHV line are proposed. Validation of the fault bulwark is performed utilizing MATLAB SIMULINK transient simulations by varying fault type and fault location.
\end{abstract}

Keywords: Travelling waves, transmission line, MATLAB/SIMULINK, protection systems.

\section{Introduction}

An electric power system comprises of generation, transmission and distribution of electric energy. Transmission lines are habituated to transmit electric power to distant immensely colossal load centers. The rapid magnification of electric power systems over the past few decades has resulted in an astronomically immense increase of the number of lines in operation and their total length. These lines are exposed to faults as a result of lightning, short circuits, faulty equipments, mis-operation, human errors, overload, and aging. Many electrical faults manifest in mechanical damages, which must be rehabilitated afore returning the line to accommodation. The renovation can be expedited if the fault location is either kenned or can be estimated with a plausible precision. Faults cause short to long term power outages for customers and may lead to consequential losses especially for the manufacturing industry[8,9]. Expeditious detecting, isolating, locating and rehabilitating of these faults are critical in maintaining a reliable power system operation. When a fault occurs on a transmission line, the voltage at the point of fault suddenly reduces to a low value. This sudden change engenders a high frequency electromagnetic impulse called the Travelling wave Theory (TWT). These peregrinating waves propagate away from the fault in both directions at speeds proximate to that of light. The paper reports work on analyzing travelling waves, which may occur on power transmission lines utilizing Bewley Lattice Diagram (BLD) [1]. High Speed Fault clearance is an efficacious method of incrementing power transfer and amending the transient stability of a potency system[2,3].

\section{Travelling wave theory}

The transmission line conductors have resistances and inductances distributed uniformly along the length of the line. Travelling wave fault location methods are conventionally more opportune for application to long lines.
Transmission lines cannot be analyzed with lumped parameters, when the length of the line is considerable compared to the wavelength of the signal applied to the line. Power transmission lines, which operate at $50-\mathrm{Hz}$ and are more than $80-\mathrm{km}$ long, are considered to have distributed parameters. These lines have the properties of voltage and current waves that travel on the line with finite speed of propagation. Travelling wave methods for transmission lines fault location have been reported since a long time. Subsequent developments employ high speed digital recording technology by utilizing the peregrinating wave transients engendered by the fault. It is well known that when a fault occurs in overhead transmission lines systems, the abrupt transmutations in voltage and current at the point of the fault engender high frequency electromagnetic impulses called peregrinating waves which propagate along the transmission line in both directions away from the fault point.These transients peregrinate along the lines and are reflected at the line terminals complying with the rules of Bewley's Lattice Diagrams [4].

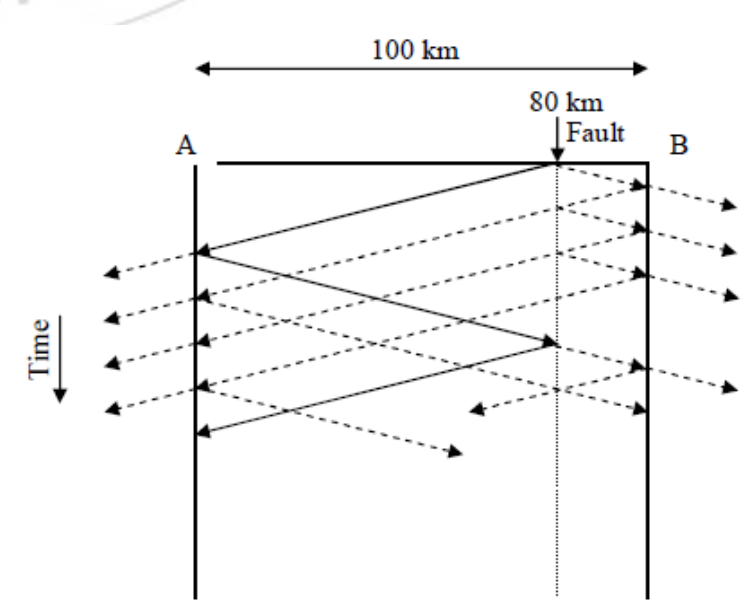

Figure1: Bewley lattice diagram 


\section{International Journal of Science and Research (IJSR) \\ ISSN (Online): 2319-7064 \\ Index Copernicus Value (2013): 6.14 | Impact Factor (2015): 6.391}

The voltage and current at any point $\mathrm{x}$ obey the partial differential equations:

$$
\begin{aligned}
& \frac{\partial e}{\partial x}=-L \partial i / \partial t \\
& \frac{\partial i}{\partial x}=-C \partial e / \partial t
\end{aligned}
$$

where $L$ and $C$ are the inductance and capacitance of the line per unit length. The resistance is assumed to be negligible. The solutions of these equations are:

$$
\begin{aligned}
& e(x, t)=e_{f}(x-v t)+e_{r}(x+v t) \\
& i(x, t)=\frac{1}{z} e_{f}(x-v t)-e_{r}(x+v t)
\end{aligned}
$$

Where $\mathrm{Z}=\sqrt{L / C}$ the characteristic impedance of the transmission is line and $V=1 / \sqrt{L C}$ is the velocity of propagation.

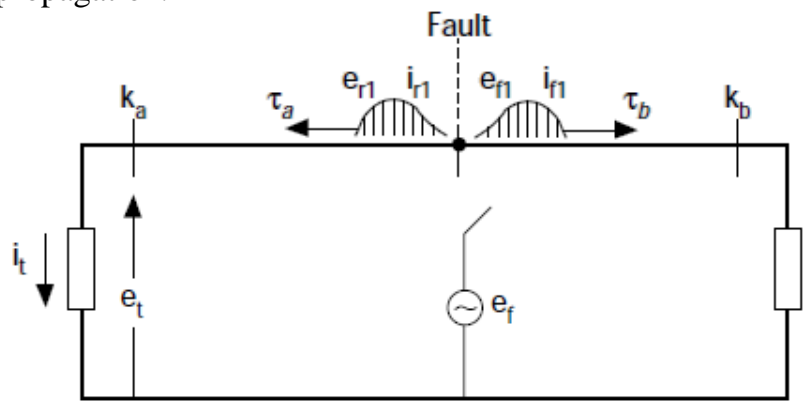

Figure2: Travelling voltage and current waves
Transmission line ends represent a discontinuity or impedance change where some of the wave's energy will reflect back to the perturbance. The remaining energy will peregrinate to other power system elements or transmission lines. The fundamental characteristics of fault engendered travelling wave transients [5] can be summarized as:

a) The wave characteristics change suddenly with the advent of successive waves at the bus bar. This marks the occurring of the fault and the peregrinating time for the peregrination from the fault to bus bar etc;

b) The magnitude of the sudden change depends on the magnitude of the voltage at the fault instant - e(t). For later waves, it withal depends on the reflection and refraction coefficients at the discontinuity and the attenuation characteristics of peregrinating wave [6]; and

c) The polarity of the sudden change depends on the polarity of the fault voltage at the fault instant and the discontinuous characteristics of the wave impedance

\section{Simulation model and its results}

For evaluating the performance of the proposed algorithm, the authors adopt MATLAB/ SIMULINK and results obtained by proposed method are shown below:

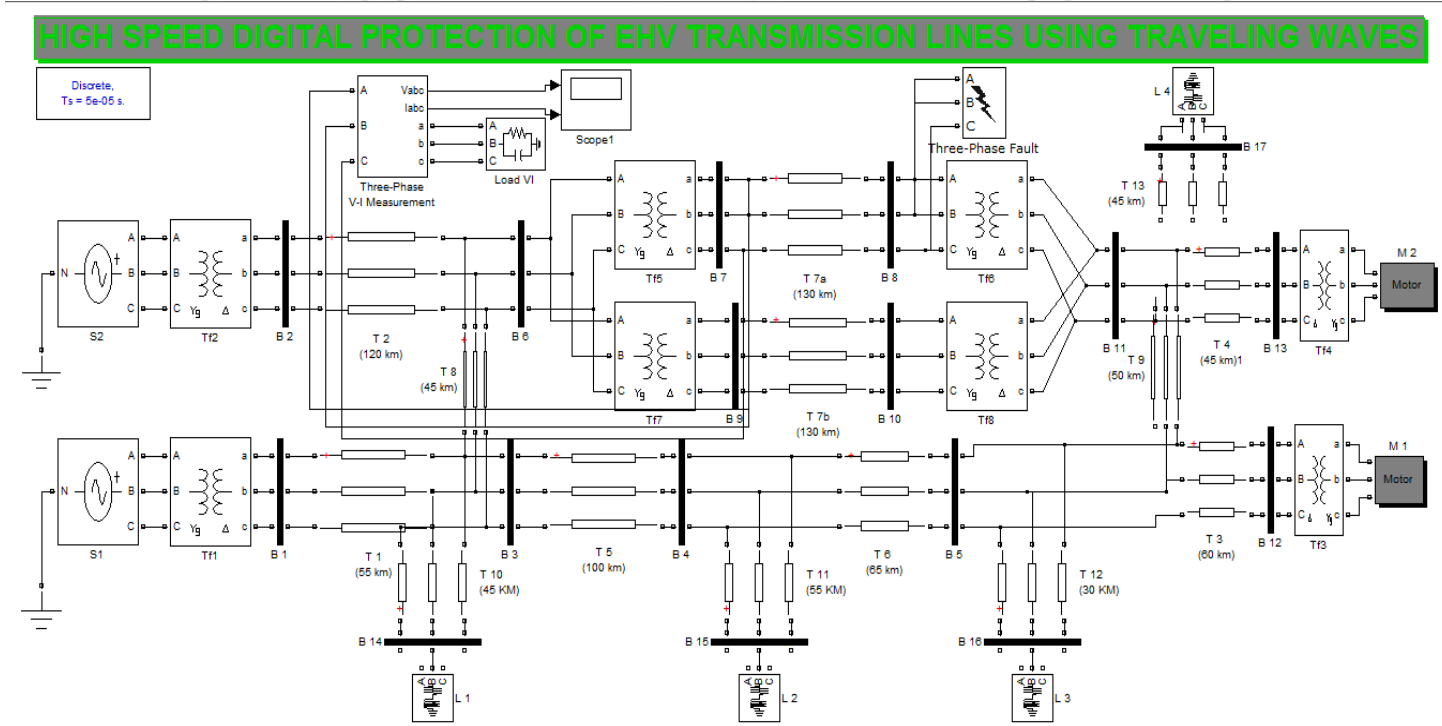

Figure 3: Test power system model in MATLAB/SIMULINK

\subsection{Case A: Fault Location by Single End Method}

In single end fault location method, the high speed digital relays or fault locators are located at the one end of the transmission line. The fault distance can be calculated by formula given below[7]:

$$
D=\frac{T_{d}}{2} * v
$$

$\mathrm{D}$ is the distance of fault, $\mathrm{T}_{\mathrm{d}}$ is the time of fault taken from the simulation results and $\mathrm{v}$ is the velocity of propagation..

Table 1: Single end method results

\begin{tabular}{|c|c|c|c|}
\hline $\begin{array}{c}\text { Fault } \\
\text { Type }\end{array}$ & $\begin{array}{c}\text { Distance of } \\
\text { Fault }(\mathrm{km})\end{array}$ & $\begin{array}{c}\text { Calculated } \\
\text { Distance }(\mathrm{km})\end{array}$ & Percentage Error \\
\hline LG & 30 & 27.94 & -1.58 \\
\hline LLG & 60 & 62.6 & 2.02 \\
\hline LL & 90 & 89.04 & -0.73 \\
\hline LLL & 120 & 119.10 & -0.69 \\
\hline
\end{tabular}


International Journal of Science and Research (IJSR)

ISSN (Online): 2319-7064

Index Copernicus Value (2013): 6.14 | Impact Factor (2015): 6.391

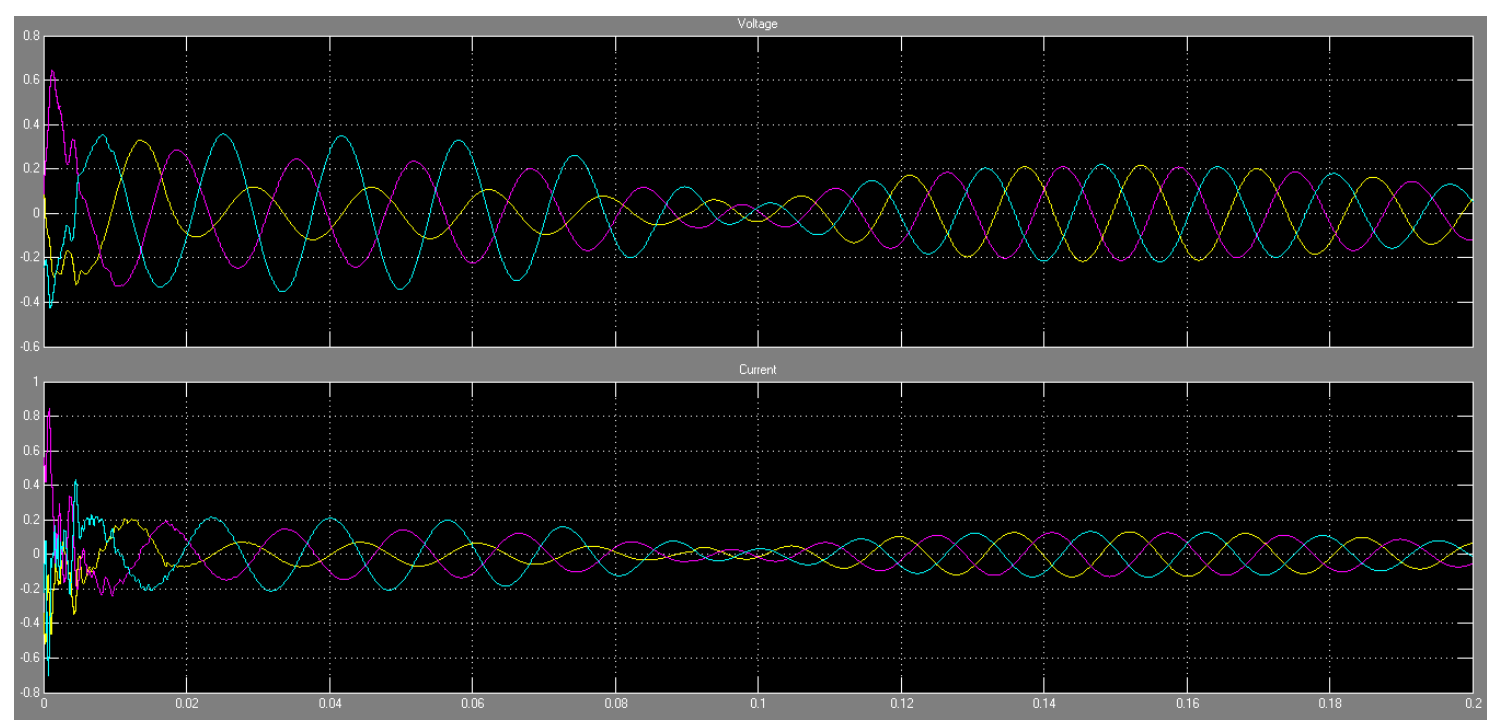

Figure 4: Voltage and current waveform at $30 \mathrm{~km}($ LG FAULT)

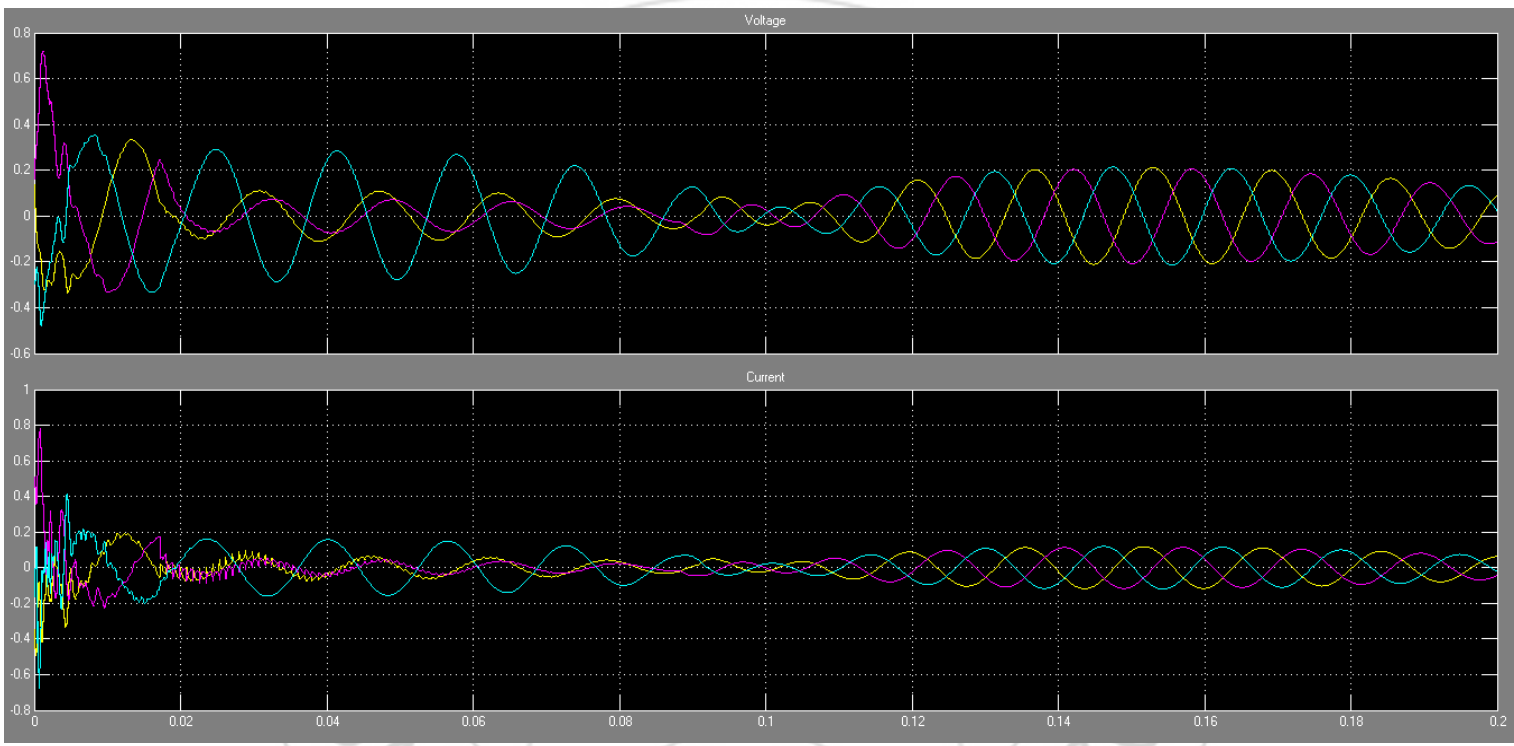

Figure 5: Voltage and current waveform at $60 \mathrm{~km}($ LLG FAULT)

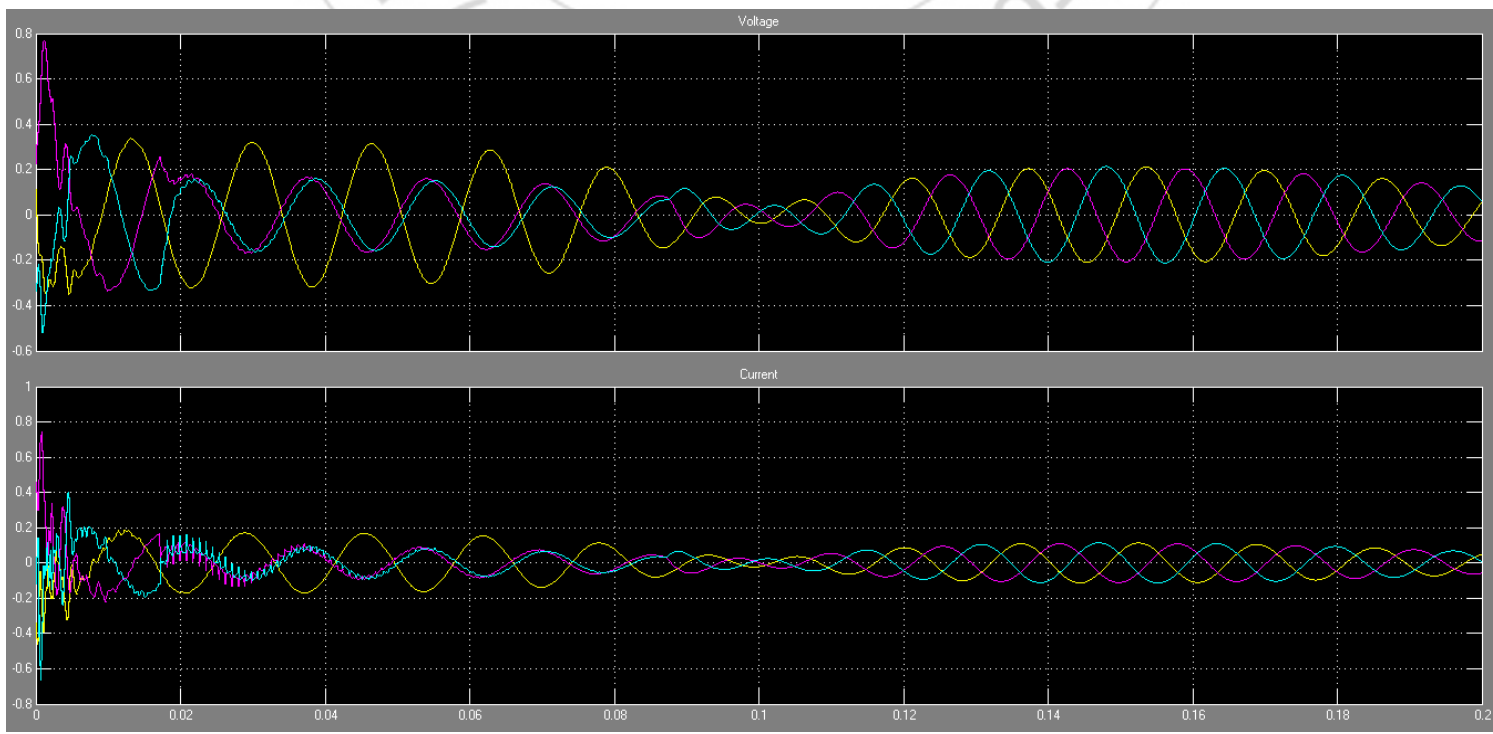

Figure 6: Voltage and current waveform at $90 \mathrm{~km}($ LL FAULT)

Volume 5 Issue 5, May 2016

www.ijsr.net 
International Journal of Science and Research (IJSR)

ISSN (Online): 2319-7064

Index Copernicus Value (2013): 6.14 | Impact Factor (2015): 6.391

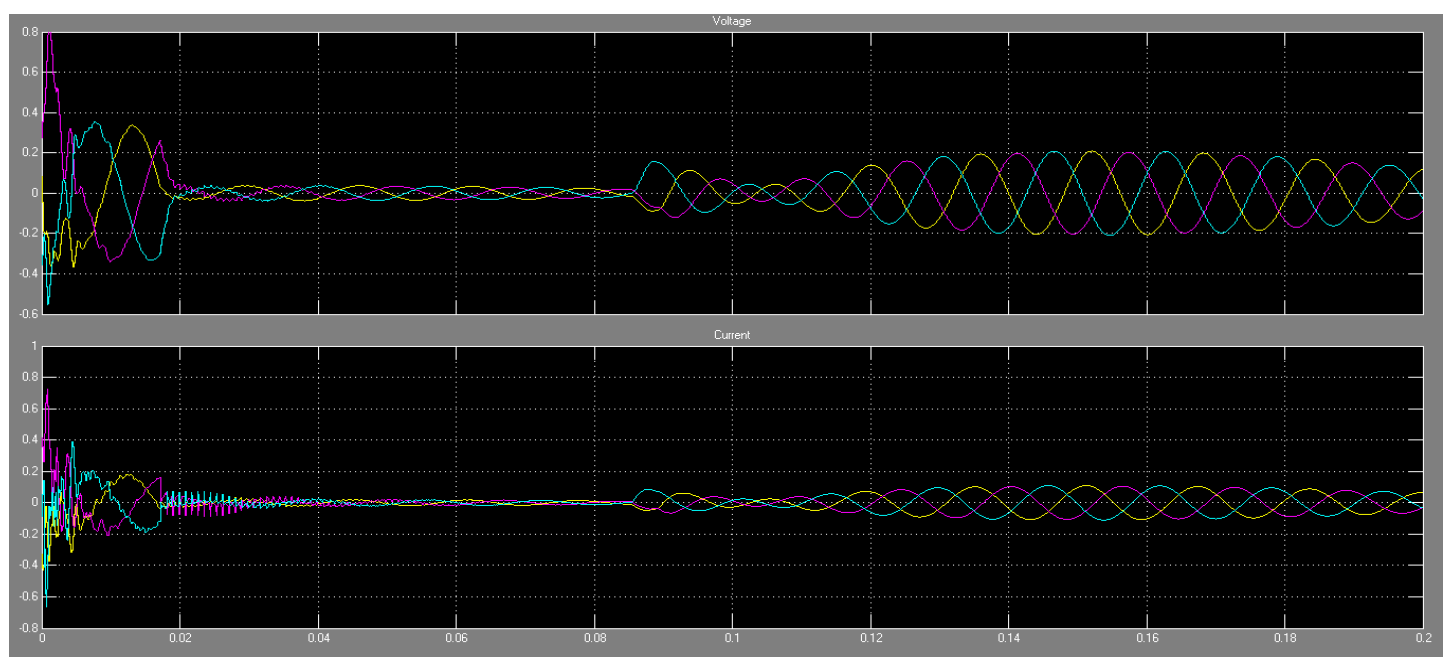

Figure 7: Voltage and current waveform at $120 \mathrm{~km}$ (LLL FAULT)

\subsection{Case B: Fault Location by Double End Method}

In double end fault location method, high speed digital relays or fault locators are located at both the terminals of the transmission line. The fault distance can be calculated by formula given below[7]:

$$
D=\left(T_{a-} T_{b}+\frac{L}{V}\right) * v / 2
$$

$\mathrm{D}$ is the distance of fault, $\mathrm{T}_{\mathrm{a}}$ and $\mathrm{T}_{\mathrm{b}}$ is the time of fault taken from simulation results, $\mathrm{L}$ is the length of transmission line and $\mathrm{v}$ is the velocity of propagation.

Table 2: Double end method results

\begin{tabular}{|c|c|c|c|}
\hline Fault Type & $\begin{array}{c}\text { Distance of } \\
\text { Fault }(\mathrm{km})\end{array}$ & $\begin{array}{c}\text { Calculated } \\
\text { Distance }(\mathrm{km})\end{array}$ & $\begin{array}{c}\text { Percentage } \\
\text { Error }\end{array}$ \\
\hline LG & 30 & 26.70 & -2.53 \\
\hline LLG & 60 & 61.56 & 1.2 \\
\hline LL & 90 & 85.34 & -3.58 \\
\hline LLL & 120 & 116.64 & -2.58 \\
\hline
\end{tabular}

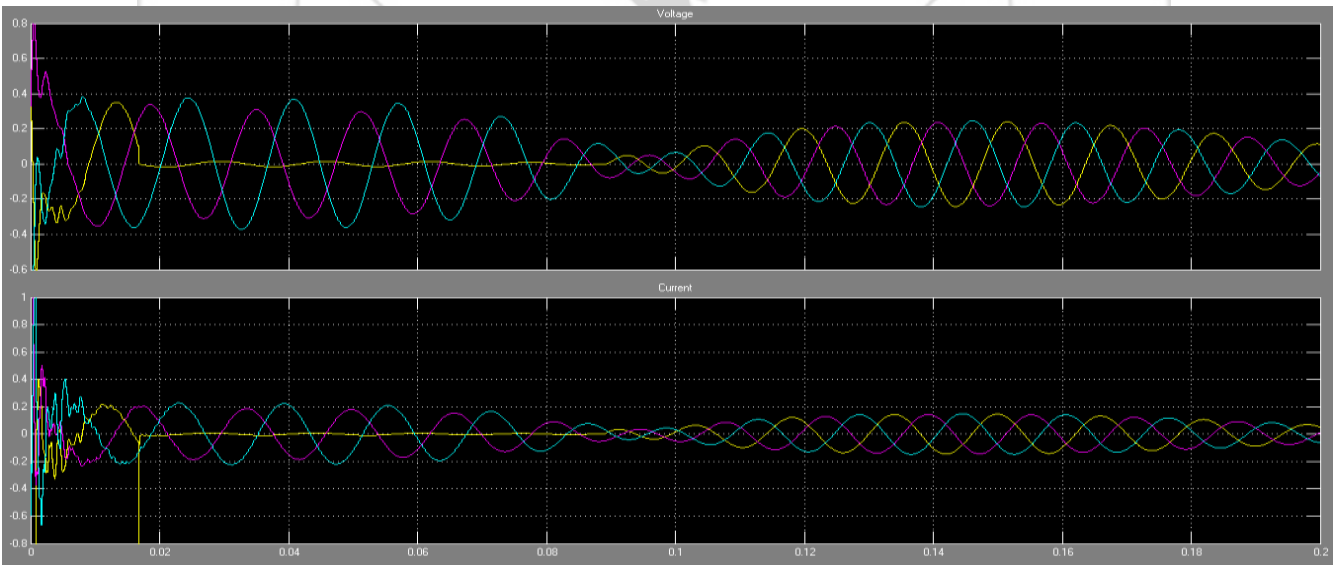

Figure 8: Voltage and current waveform at $30 \mathrm{~km}$ (LG FAULT)

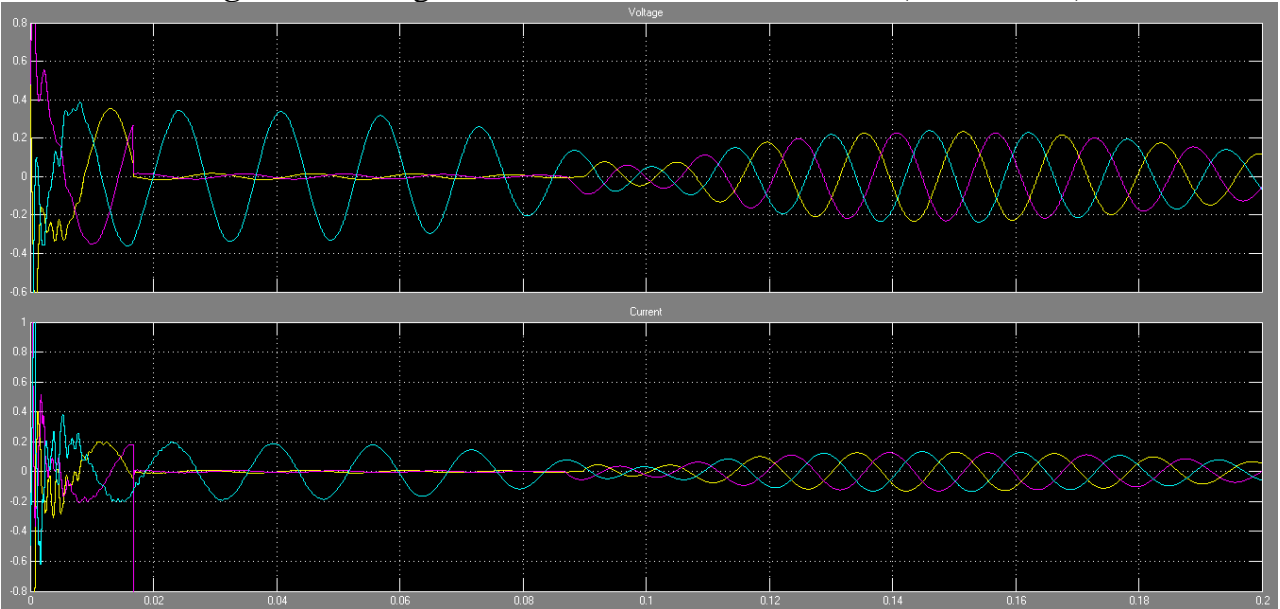

Figure 9: Voltage and current waveform at 60km (LLG FAULT)

Volume 5 Issue 5, May 2016 www.ijsr.net 


\section{International Journal of Science and Research (IJSR)}

ISSN (Online): 2319-7064

Index Copernicus Value (2013): 6.14 | Impact Factor (2015): 6.391

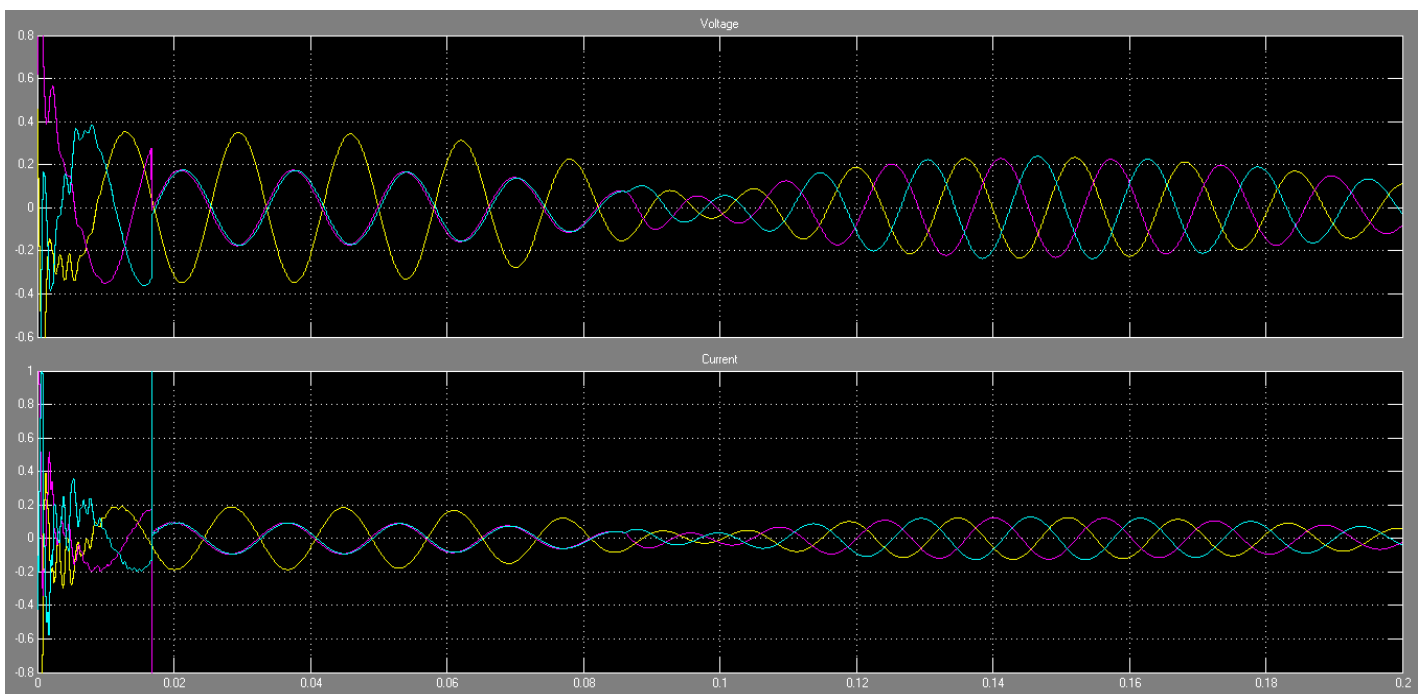

Figure 10: Voltage and current waveform at $90 \mathrm{~km}$ (LL FAULT)

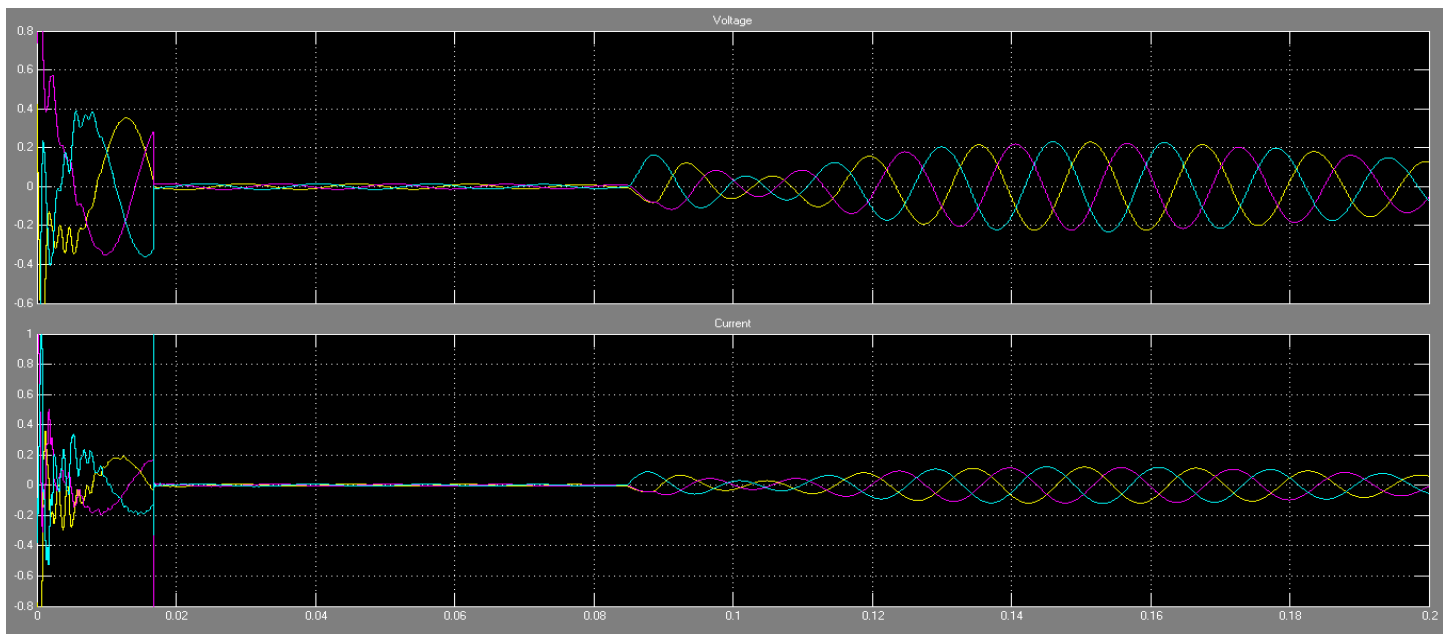

Figure 11: Voltage and current waveform at $120 \mathrm{~km}$ (LLL FAULT)

\section{Conclusion}

In this paper fault locator has been presented which is predicated on the characteristics of the travelling waves initiated from the fault. This component of the work has addressed the quandary of fault distance estimation utilizing the quantifications of currents as well as voltage travelling wave signals in single area and two area transmission line systems. The travelling wave theory was introduced and the properties of the travelling waves on transmission lines were additionally discussed. The main objective of this work is to propose an automated technique predicated on travelling waves for finding the fault location in transmission lines and to test the performance of the technique. The techniques were tested utilizing data engendered by executing sundry cases in MATLAB/SIMULINK. Sundry types of faults were applied at sundry locations on the transmission lines. Conclusively it is shown that the proposed method is precise enough to be utilized in detection of transmission line fault location. It is possible to achieve more preponderant precision with multi end methods compared to other fault location method.

\section{References}

[1] L.V. Bewley. 1951. Traveling waves on transmission systems. Wiley, New York.

[2] D. Spoor and J. G. Zhu. 2006. Improved single-ended travelling-wave fault-location algorithm based on experience with conventional substation transducers. IEEE Transactions on Power Delivery. 21: 1714-1720.

[3] T. Takagi, Y. Yamakoshi, M. Yamura, R. Kondow and T. Matsushima. 1982. Development of a new type fault locator using the one terminal voltage and current data. IEEE Trans. Power Apparent. Syst., PAS-101: 28922898.

[4] Vajira Pathirana, "A power system protection scheme combining impedance measurement \& travelling waves: software \& hardware implementation", Ph.D. Thesis, University of Manitoba, Canada, April 2004

[5] Elhaffar N. I. Elkalashy, M. Lehtonen. 2007. Experimental Investigations on Multi-end Fault Location System based on Current Travelling waves. Power Tech 2007. Lausanne, Switzerland

[6] D. Spoor and J. G. Zhu. 2006. Improved single-ended travelling-wave fault-location algorithm based on experience with conventional substation transducers. IEEE Transactions on Power Delivery. 21: 1714-1720 
[7] D.C.Idoniboyeobu and P.O.Ohiero High Speed Protection of Extra high voltage(EHV) Transmission Line using Digital Travelling Waves International Journal of Academic Research vol .3. no.5 september 2011.

[8] Vinay K Gupta, Sanjay Mittal , Pawan Kumar Method for Transmission Line Fault Location International Jouranal for Technological Research in Engineering vol.2, Issue 9, May 2015.

[9] Ugwu, Malachy Amechi, Ezechukwu, O.A; Enesi, David O Fault Location in Extra High Voltage Transmission Line Case Study: Onitsha -New Haven Enugu $330 \mathrm{kv}$ Transmission line International Journal of Emerging Technology and Advanced Engineering vol 5, Issue9, September 2015.

\section{Author Profile}

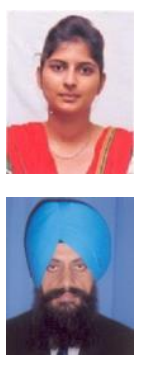

Harpreet Kaur received B.Tech degree in Electrical Engg. in 2014 from BBSBEC, Fatehgarh Sahib. She is currently pursuing her. M. Tech from same institute. Her research interest includes power system protection

Gursewak Singh Brar received his M.Tech in Electrical Engineering in 2003 from GNDEC Ludhiana. He received his Ph.D. in Electrical Engg. from PTU Jalandhar in Feb. 2010. He is currently working as associate professor and $\mathrm{Head}$ of Department in Electrical Engg. Deptt. at BBSBEC, Fatehgarh Sahib $(\mathrm{Pb}$.).His research interest includes Electrical Instrumentation and Control Engineering using Soft Computing Techniques and Power System Optimization

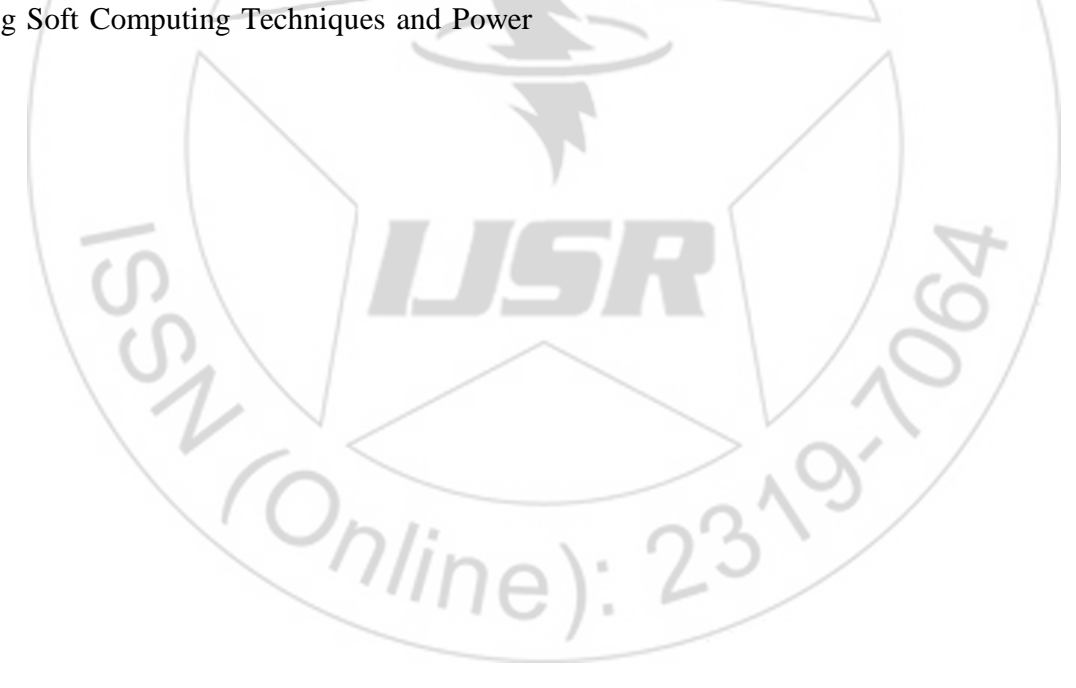

